\title{
ANALISA DAN PERANCANGAN SISTEM PEMBELAJARAN ONLINE MENGGUNAKAN METODE PARSING
}

\author{
Hidayatulah Himawan \\ Jurusan Teknik Informatika UPN "Veteran" Yogyakarta \\ Jl. Babarsari 2 Tambakbayan 55281 Telp (0274) 485323 \\ e-mail : if.iwan@gmail.com
}

\begin{abstract}
Learning system that effectively and efficiently into the output (output) is desired by each of the components involved in the education world. One of the learning system developed at this time is a distance learning or commonly referred to as e-learning. The system of distance learning or e-learning has been developed by academics, but what is desired for the educational system can be run more effectively and efficiently without reducing the quality of that output is still very far from what is expected. The methods and ways that run on this research uses analysis tool of the results of a survey of systems developed. Results were analyzed to see kecndrungan of a system if it serves the user, for this reason, this research will develop the processing of data on patterns of development of knowledge through online learning systems.

Keywords : Online Learning System, Elearning, Online System

Sistem pembelajaran yang efektif dan efisien menjadi output (keluaran) yang diinginkan oleh tiap komponen yang terlibat di dalam dunia pendidikan. Salah satu sistem pembelajaran yang berkembang saat ini adalah pembelajaran jarak jauh atau yang biasa disebut dengan $e-$ learning. Sistem pembelajaran jarak jauh atau e-learning banyak dikembangkan oleh kalangan akademik, namun apa yang diinginkan agar sistem pendidikan bisa berjalan lebih efektif dan efisien tanpa mengurangi kualitas output yang dihasilkan masih sangat jauh dari apa yang diharapkan. Metode dan cara yang dijalankan pada penelitian ini menggunakan alat analisa berupa hasil survey terhadap sistem yang dikembangkan. Hasil itu dianalis untuk dilihat kecndrungan dari suatu sistem jika melayani pengguna, untuk itulah, penelitian ini akan mengembangkan pengolahan data pada pengembangan pola pengetahuan melalui sistem pembelajaran online.

Kata Kunci : Sistem Pembelajaran Online, Elearning, Sistem Online.
\end{abstract}

\section{PENDAHULUAN}

Sistem pembelajaran memiliki banyak variasi pada penerapannya. Secara umum pembelajaran memiliki proses yang efektif dan efisien dalam proses yang dijalankan. Keinginan agar proses pembelajaran menjadi lebih praktis tanpa mengurangi fungsi pembelajaran adalah tujuan yang hendak dicapai oleh tiap komponen pembelajaran. Salah satu sistem pembelajaran yang dikembangkan pada saat ini adalah sistem pembelajaran online. Pembelajaran online memiliki banyak definisi. Namun secara aplikatif sistem pembelajaran online adalah suatu model pembelajaran yang menggunakan media internet secara online melalui web, sehingga proses pembelajaran dilakukan secara tidak langsung atau tanpa tatap muka antara pendidik dan siswa.

Sistem pembelajaran online membutuhkan teknologi pendukung yang mampu memproses berbagai aplikasi permintaan yang diberikan oleh pengguna. Salah satu teknologi yang dapat dikembangkan adalah penggunaan basis data pada sistem pembelajaran online. Basis data menjadi salah satu komponen teknologi yang harus dapat mengolah berbagai data dan aktifitas permintaan informasi yang diberikan oleh pengguna.

\section{DASAR TEORI}

\subsection{Pola dan Data Mining}

Pengenalan pola adalah suatu disiplin ilmu yang mempelajari cara-cara mengklasifikasikan objek ke beberapa kelas atau kategori dan mengenali kecendrungan data. Tergantung pada aplikasinya, objek ini bisa berupa pasien, mahasiswa, pemohon kredit, image 
atau signal atau pengukuran lain yang perlu diklasifikasikan atau dicari fungsi regresinya. Biasanya subjek ini disebut dengan pengenalan pola atau pattern recognition. Pada proses pengenalan pola di data mining ini, pola yang terbentuk berdasarkan kategori data yang telah ditentukan oleh para pengembang sistem. Pola ini bisa berdasarakan pada pola pencarian data, pola akses data, maupun pola penggunaan dan kinerja sistem yang dikembangkan.

\subsection{Metoda Parsing}

Grammar adalah deskripsi formal suatu bahasa. Chomsky membagi grammar menjadi 4 tipe, dan hampir semua bahasa pemrograman merupakan bahasa dengan grammar tipe 2 (context-free grammar). Umumnya grammar context free dinyatakan dalam notasi BNF (Backus Naur Form) atau EBNF (Extended BNF). Sebuah unit dalam sebuah bahasa disebut sebagai token. Sebuah token biasanya adalah sebuah kata atau simbol. Sesuatu literal seperti koala atau kursi yang tidak bisa dipecah lagi disebut sebagai terminal. Parsing (syntactic analysis) adalah proses untuk menganalisis token dalam menentukan struktur grammarnya. Proses parsing biasanya terdiri dari dua bagian. Bagian pertama adalah yang menggabungkan karakter demi karakter untuk membuat token. Biasanya dilakukan oleh bagian yang disebut scanner atau lexer. Bagian kedua adalah yang menentukan apakah token tersebut memenuhi grammar yang dilakukan oleh bagian yang disebut parser.

\subsection{Parsing Top-Down}

Ada 2 kelas metoda parsing top-down, yaitu kelas metoda dengan backup dan kelas metoda tanpa backup. Contoh metoda kelas dengan backup adalah metoda Brute-Force, sedangkan contoh metoda kelas tanpa backup adalah metoda recursive descent.

a. Metoda Brute-Force

Kelas metoda dengan backup, termasuk metoda Brute-Force, adalah kelas metoda parsing yang menggunakan produksi alternatif, jika ada, ketika hasil penggunaan sebuah produksi tidak sesuai dengan simbol input. Penggunaan produksi sesuai dengan nomor urut produksi. Metoda Brute-Force tidak dapat menggunakan grammar rekursi kiri, yaitu grammar yang mengandung produksi rekursi kiri (left recursion). Produksi rekursi kiri akan menyebabkan parsing mengalami looping tak hingga.

b. Metoda Recursive-Descent

Kelas metoda tanpa backup, termasuk metoda recursive descent, adalah kelas metoda parsing yang tidak menggunakan produksi alternatif ketika hasil akibat penggunaan sebuah produksi tidak sesuai dengan simbol input. Ketentuan produksi yang digunakan metoda recursive descent adalah : Jika terdapat dua atau lebih produksi dengan ruas kiri yang sama maka karakter pertama dari semua ruas kanan produksi tersebut tidak boleh sama.

\subsection{Variabel, Fitur dan Attribute}

Suatu observasi, example, pattern (pola) atau objek biasanya ditandai oleh beberapa attribute. Misalnya objek orang ditandai dengan attribute tinggi badan, jenis kelamin, warna kulit, bentuk muka, atau lain sebagainya. Attribute ini sering disebut dengan variable. Juga ada yang menyebutnya sebagai suatu fitur. Jadi ketiga hal tersebut adalah sama. Dari sederet variabel akan dikelompokkan menjadi input (variabel independent, predictor) dan output (variabel dependent, response atau label). Format data dinyatakan dalam bentuk matriks dimana baris menyatakan objek atau observasi dan kolom menyatakan attribute atau fitur atau variabel. Proses pengurangan dimensi data sering disebut sebagai feature extraction dan feature selection. Kedua istilah ini mengurangi dimensi variabel atau kolom dari data.

\subsection{Supervised dan Unsupervised Learning}

Metode pembelajaran (learning) secara umum dibagi ke dalam dua pendekatan. Yaitu supervised dan unsupervised. Pada pendekatan unsupervised learning, metode dapat diterapkan tanpa adanya latihan (training) dan tanpa guru (teacher). Guru disini adalah label dari data. Misalkan kita punya sekolompok pengamatan atau data tanpa label (output) tertentu, maka dalam unsupervised learning kita mengelompokkan data tersebut ke dalam beberapa kelas yang kita kehendaki. Ini dilakukan karena data yang ada memang tidak mempunyai label. Label menandai kemana data dikelompokkan. Untuk melakukan tugas (task), dapat diterapkan metode unsupervised learning. Metode yang termasuk didalam kelompok ini adalah metode klastering dan self organizing map (SOM). 


\section{METODE DAN ALAT PENELITIAN}

\subsection{Jalan Penelitian}

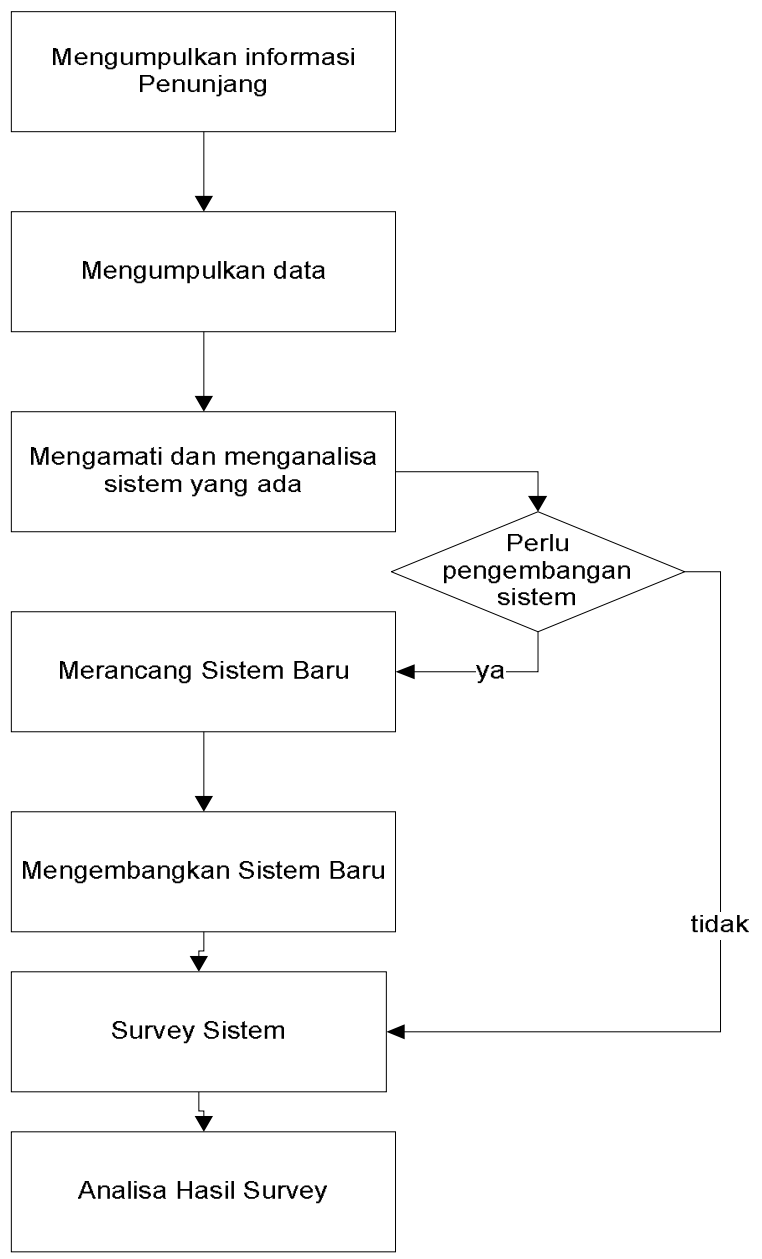

Gambar 3.1. Gambar jalannya penelitian.

\subsection{Diagram Konteks}

Sistem pembelajaran online yang dikembangkan oleh peneliti, memiliki aktor yang terdiri dari Admin, Dosen dan mahasiswa. Ketiga aktor ini berinteraksi di dalam sistem sesuai dengan hak akses yang ada pada sistem. Ketiga aktor memberikan data yang mengalir pada sistem. Adapun aliran data yang terjadi dapat dilihat pada Gambar 3.2. 


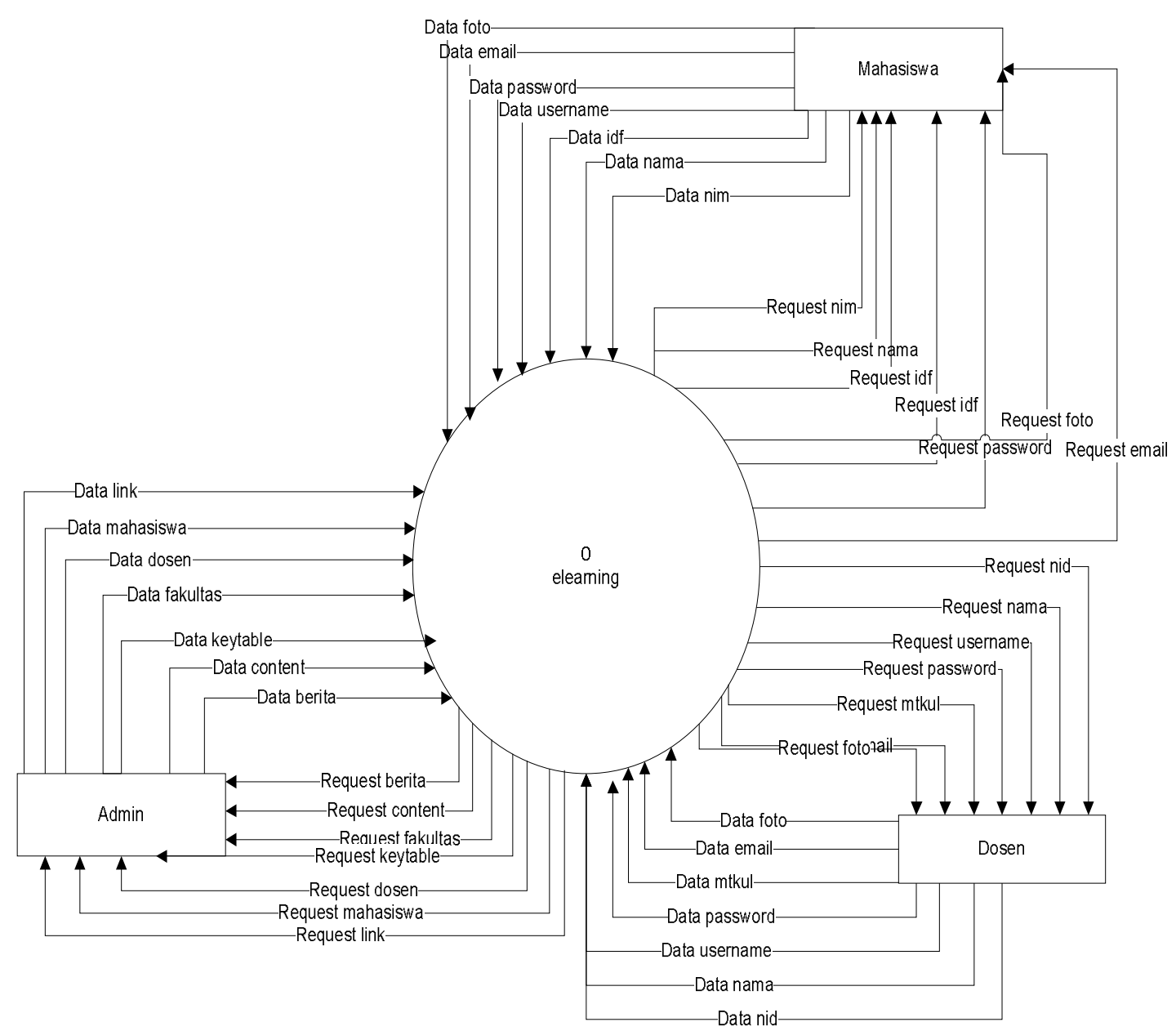

Gambar 3.2. Diagram Konteks Sistem Pembelajaran Online

Gambar 3.2 memperlihatkan fungsi tiap aktor dan peran yang berbeda antara yang satu dengan yang lainnya. Fungsi dosen berbeda dengan fungsi yang didapat oleh mahasiswa. Dosen memiliki aktifitas untuk meng-upload data atau materi perkuliahan. Sedangkan mahasiswa memiliki fungsi untuk dapat men-download materi yang ada. Admin memiliki fungsi dan otoritas yang lebih lengkap atau kompleks. Karena secara umum, admin memiliki tanggung jawab terhadap jalannya sistem. Untuk lebih jelasnya, sistem dapat dikembangkan pada DFD level yang lebih tinggi.

\subsection{DFD Level 0}

Pada DFD level 0 terlihat bahwa aktor memiliki peranan penting dalam aliran data yang terjadi. Aliran data akan diproses dan disimpan ke dalam database yang telah disediakan. Dari data yang didapat, maka akan dianalisa sesuai dengan kebutuhan penelitian.

Proses yang terjadi disetiap aktor berjalan sesuai dengan fungsinya. Fungsi yang terjadi selalu berhubungan dengan komponeen utama dari tiap proses yang ada. Secara garis besar, proses yang berjalan dapat dilihat Gambar 3.3 di bawah ini. 


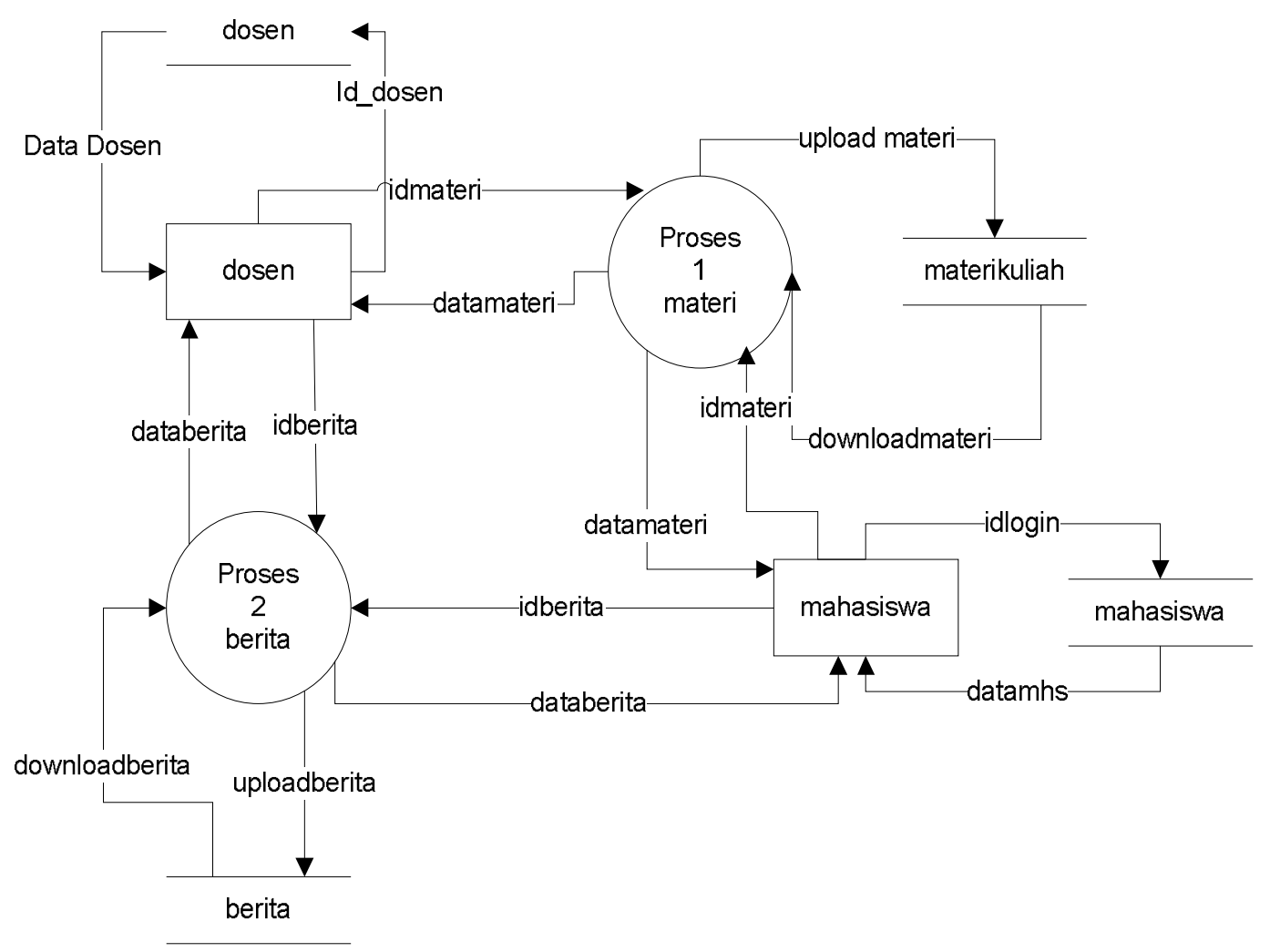

Gambar 3.3. DFD Level 0 Sistem Pembelajaran Online Dosen dan Mahasiswa

Gambar 3.3 memperlihatkan bahwa mahasiswa dapat melakukan login sesuai dengan id data yang dimiliki. Dari login tersebut user dapat melakukan proses pencarian data materi perkuliahan atau mata kuliah yang dilaksanakan pada sistem yang dijalankan.

Login yang diberikan pada dosen memiliki fungsi khusus untuk melakukan upload materi perkuliahan. Materi perkuliahan yang ada masuk ke dalam database sesuai dengan jenis dan kelompok yang diberikan.

\subsection{DFD Level 1 Mahasiswa}

Pada DFD level 1, secara garis besar sistem dirancang terbagi atas dua (2), yaitu sistem yang melibatkan secara langsung antara mahasiswa dengan sistem, dan sistem yang ada pada admin. Adapun DFD level 1 nya bisa dilihat pada Gambar 3.4 di bawah ini. 


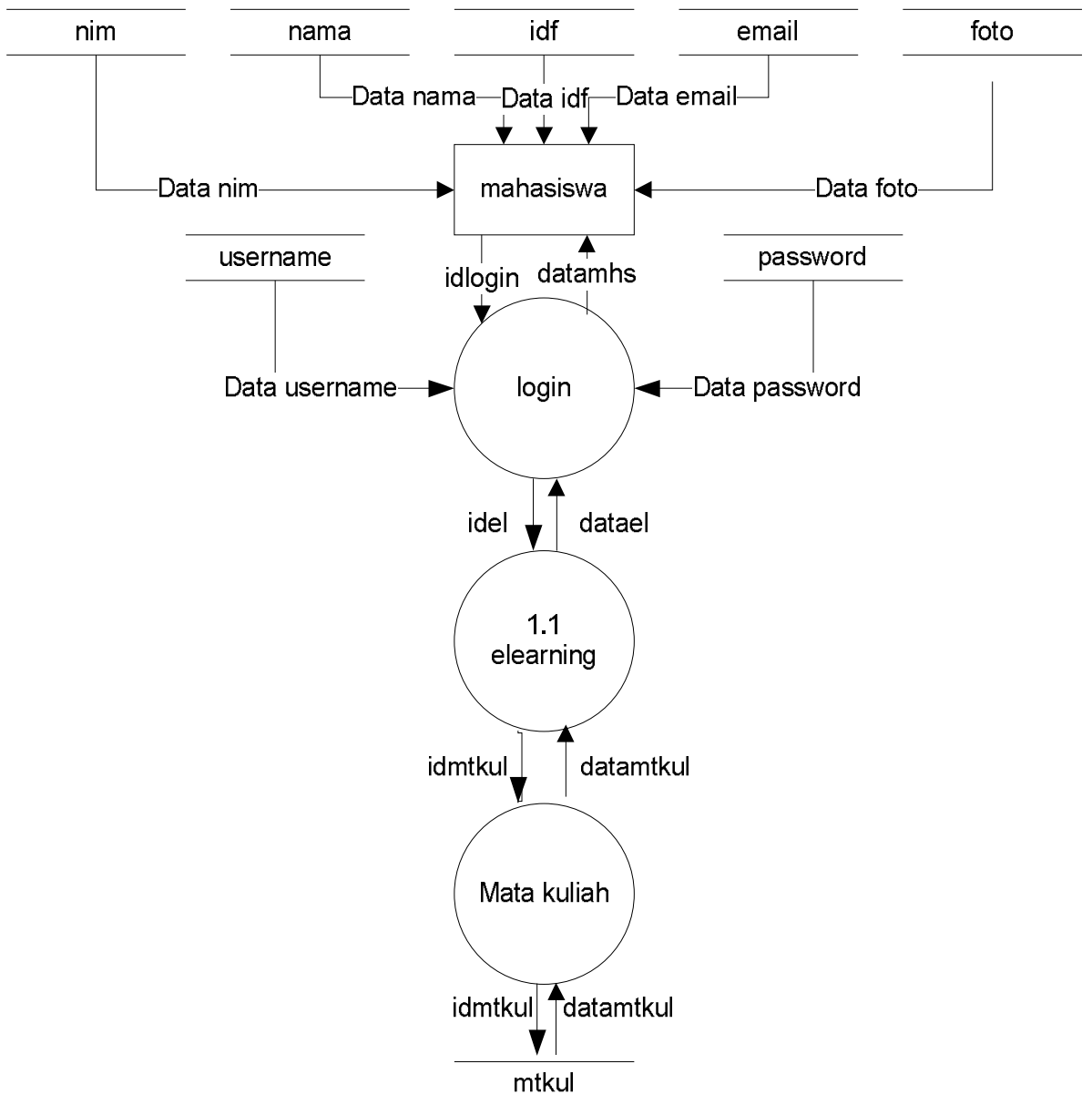

Gambar 3.4. DFD Level 1 Sistem Pembelajaran Online Mahasiswa

Gambar 3.4 menunjukkan bahwa mahasiswa dapat mengambil mata kuliah yang ada pada sistem setelah melakukan login sesuai dengan hak akses yang diberikan. Login pada tiap mahasiswa memiliki ketentuan proses sesuai dengan ketersediaa menu yang ada. Batasan hak akses diberikan kepada pengguna untuk menjaga sistem dari gangguan yang tidak diharapkan.

\subsection{Rancangan Tabel pada sistem}

Rancangan tabel akan menentukan struktur yang akan digunakan pada database baik dari field yang ada, serta panjang data yang akan dimasukkan ke dalam sistem. Selain itu akan ditetapkan pula primary key pada setiap tabel yang dibuat.

\subsubsection{Tabel Administrator}

Tabel administrator menjadikan Idadmin sebagai primary key pada sistem yang dijalankan. Sehingga admin memiliki kemampuan dalam penggunaan sistem yang sesuai dengan hak yang diberikan. Adapun tabel tersebut dapat dilihat pada Tabel 3.1.

Tabel 3.1. Tabel Administrator

\begin{tabular}{|l|l|l|l|}
\hline Field & Type & Panjang & Keterangan \\
\hline Idadmin & Int & 11 & Primary key \\
\hline Nama & Varchar & 45 & \\
\hline Username & Varchar & 10 & \\
\hline Password & Varchar & 10 & \\
\hline Email & Varchar & 45 & \\
\hline Foto & Varchar & 45 & \\
\hline
\end{tabular}


Tabel 3.1 memperlihatkan bahwa admin memiliki identitas yang berbeda berdasarkan idadmin yang ada. Sehingga pemrosesan setiap data yang masuk akan dilakukan oleh admin. Admin memiliki fungsi untuk mengelola sistem secara keseluruhan.

\subsubsection{Tabel Berita}

Table berita merupakan tempat untuk kumpulan berita pada sistem. Berita ini dimasukkan ke dalam sistem oleh admin yang memiliki hak akses untuk pengelolaan berita.

Tabel 3.2. Tabel Berita

\begin{tabular}{|l|l|l|l|}
\hline Field & Type & Panjang & Keterangan \\
\hline Idberita & Int & 11 & Primary key \\
\hline Judul & Varchar & 45 & \\
\hline Deskripsi & Varchar & 100 & \\
\hline Isi & Text & & \\
\hline Gambar & Varchar & 45 & \\
\hline Idadmin & Int & 11 & \\
\hline Tgl & Datetime & & \\
\hline
\end{tabular}

Tabel 3.2. memperlihatkan bahwa idberita menjadi primary key di dalam sistem. Idberita ini memberikan perbedaan antara berita yang satu dengan berita yang lainnya. Berita yang diberikan dapat diperbaiki dengan memanggil id yang ada.

\subsubsection{Tabel Content}

Tabel content merupakan kumpulan content yang ada pada sistem. Pada tabel ini terdapat informasi mengenai jumlah frekuensi pada tiap aplikasi yang dibuka ataupun dibaca oleh user. Sehingga data tentang penggunaan content akan tercatat dan tersimpan secara langsung.

Tabel 3.3. Tabel Content

\begin{tabular}{|l|l|l|l|}
\hline Field & Type & Panjang & Keterangan \\
\hline Contid & mediumint & 9 & Primary key \\
\hline Title & Text & & \\
\hline Abstract & Longtext & & \\
\hline Nmfile & Varchar & 100 & \\
\hline Frekuensi & Int & 11 & \\
\hline Size & Int & 11 & \\
\hline Tipe & Varchar & 45 & \\
\hline Nid & Char & 9 & \\
\hline Tgl & Datetime & & \\
\hline
\end{tabular}

Tabel 3.3 memperlihatkan terlihat bahwa contid menjadi primary key di dalam tabel. Sehingga tiap data yang masuk akan tercatat secara langsung oleh sistem.

\subsubsection{Tabel Dosen}

Tabel dosen merupakan kumpulan data dosen. Dosen memiliki login tersendiri untuk mengelola sistem perkuliahan yang ada. Sehingga ada perbedaan antar dosen untuk mengakses fasilitas yang ada.

Tabel 3.4. Tabel Dosen

\begin{tabular}{|l|l|l|l|}
\hline Field & Type & Panjang & Keterangan \\
\hline Nid & Char & 11 & Primary key \\
\hline Nama & Varchar & 100 & \\
\hline Username & Varchar & 10 & \\
\hline Password & Varchar & 10 & \\
\hline Mtkul & Varchar & 200 & \\
\hline Email & Varchar & 45 & \\
\hline Foto & Varchar & 45 & \\
\hline
\end{tabular}


Tabel 3.4 memperlihatkan bahwa nid menjadi primary key. Dosen harus memiliki nid jika ingin mengakses data yang ada pada sistem. Hak yang diberikan oleh sistem kepada dosen terbatas untuk melakukan upload terhadap materi atau bahan perkuliahan yang diampunya. Dosen tidak memiliki hak untuk menentukan user yang berhak mendownload materi yang dimilikinya. Dengan kata lain, siapapun yang berhasil login sebagai mahasiswa, maka user itu memiliki hak untuk men-download materi yang ada.

\subsection{Entity Relationship Diagram (ERD) E-Learning}

Dari rancangan tabel di atas, maka dapat dibuat Entity Relationship Diagram ELearning pada sistem yang ada. ERD tersebut memiliki tingkat hubungan yang berbeda antar tabelnya. Sehingga jenis hubungan memiliki derajat yang berbeda pula.

Derajat hubungan yang terbentuk bisa merupakan 1 to many, ataupun many to many. Derajat hubungan tersebut dapat dilihat pada Gambar 3.6.

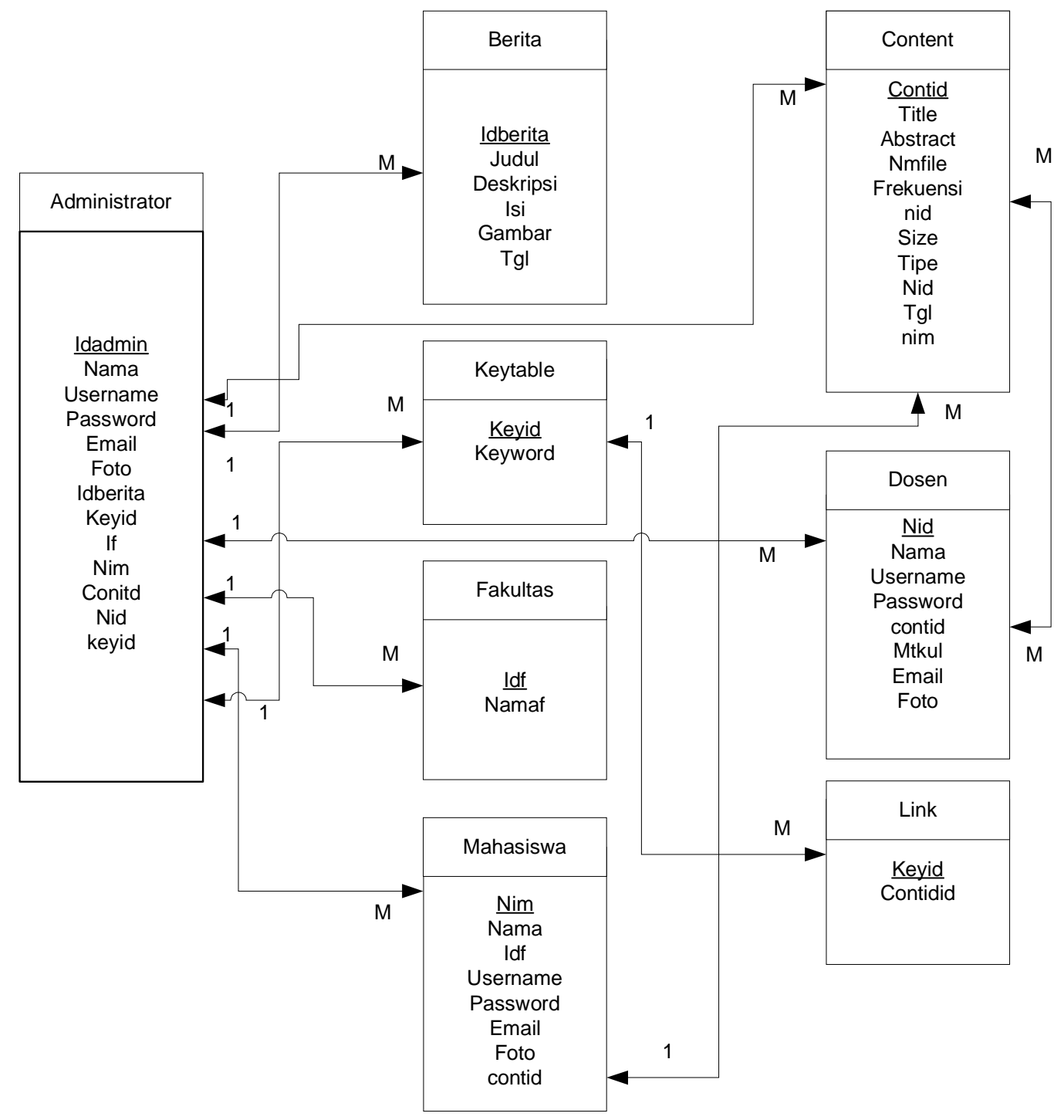

Gambar 3.6. ERD E-Learning

Gambar 3.6 memperlihatkan bahwa hubungan yang terbentuk pada tiap tabel memiliki derajat hubungan yang berbeda. Dapat kita lihat bahwa tiap dosen memiliki 1 id yang digunakan untuk tiap dosennya. Dan mahasiswa memiliki 1 id untuk login. Sehingga akan dapat dihindari terjadinya duplikat login pada user yang ada. 


\section{FLOWCHART SISTEM}

Proses utama yang dilakukan pada penelitian ini adalah proses parsing. Proses parsing dilakukan untuk memilah data yang ada pada dokumen. Proses flowchart dapat dilihat pada gambar 5.1. di bawah ini.

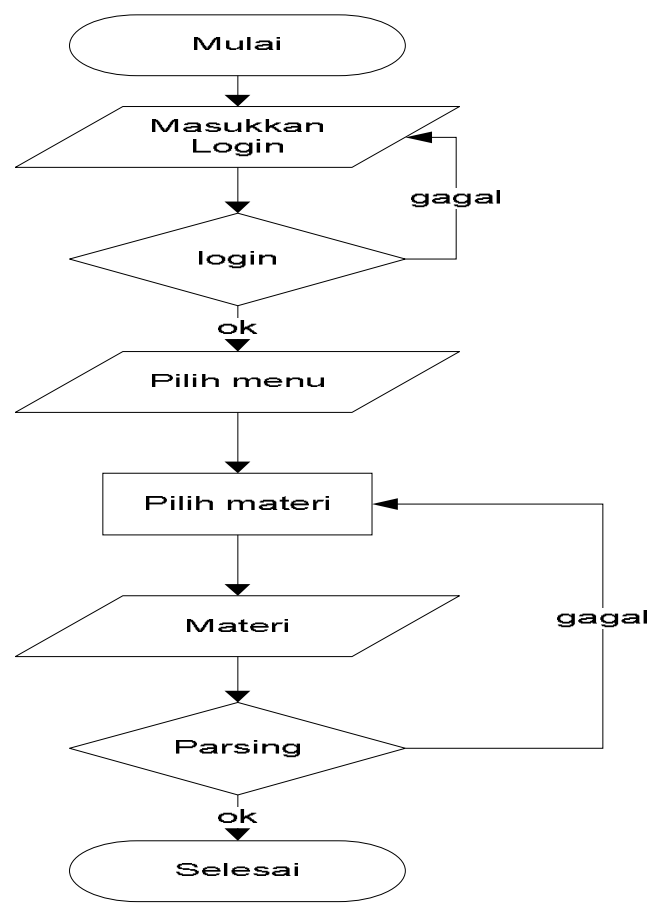

Gambar 5.1. Flow Chart untuk Proses Parsing

Gambar 5.1 memperlihatkan proses parsing yang dilakukan oleh dosen ketika sudah masuk ke dalam sistem mempergunakan fasilitas login yang diberikan. Proses pseudocodenya dapat dilihat pada Gambar 5.2.

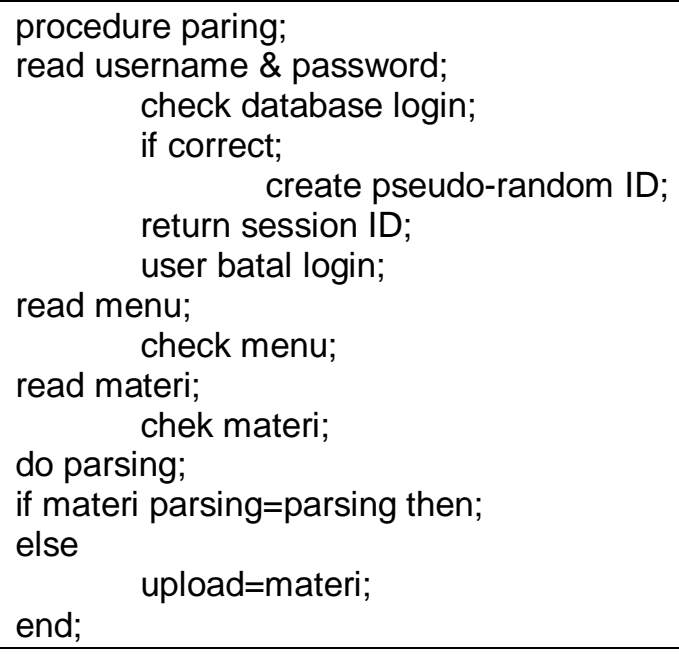

Gambar 5.2. Gambar Pseudocode

\section{KESIMPULAN}

Dari penelitian yang ada, maka dapat diambil kesimpulan sebagai berikut :

1. Berhasil dirancang sistem pembelajaran online yang user friendly dengan menggunakan metode parsing. 
2. Perancangan sistem dilakukan terutama pada proses pencarian data atau bahan perkuliahan.

3. Perancangan sistem ini dapat dikembangankan kepada pembangunan sistem pembelajaran online.

Perancangan sistem penelitian ini tidak terbatas hanya pada sistem pembelajaran online, namun bisa diberikan pada sistem lainnya.

\section{DAFTAR PUSTAKA}

Armadyah A., 2008, Perancangan dan Pembuatan Data Warehouse pada Perpustakaan STMIK Amikom Yogykarta,MTI Universitas Gadjah Mada, Yogyakarta.

Herlina T., 2007, Pengolahan dan Pemerapan Data Mining untuk Sistem Pendukung Keputusan dalam Kegiatan Akademik di MMTC Yogyakarta, Teknik Elektro UGM, Yogyakarta.

Kadir, A., 2003, Pengenalan Sistem Informasi, Andi Offset, Yogyakarta.

Kusrini, Emha Taufiq Luthi, 2009, Algoritma Data Mining, Andi Offset, STMIK Amikom, Yogyakarta

Nugroho, B., 2008, Aplikasi E-Learning dengan PHP \& Editor Dreamweaver, Universitas Atma Jaya Yogyakarta, Yogyakarta.

Poniah, P., 2001, Data Warehouse Fundamentals : A Comprehensive Guide for IT Professional. New York : John Wiley \& Sons

Purbo, Onno W., Wahyudi, Aang Arif, 2001, Mengenal E-Commerce, Elex Media Komputindo, Jakarta

Sanjaya, R., Leong., M., 2008, Mudah Membangun WEB E-Learning, Universitas Atma Jaya Yogyakarta, Yogyakarta

Santosa, B., 2007, Data Mining Teknik Pemanfaatan Data untuk Keperluan Bisnis, Graha IImu, Edisi Pertama, Yogyakarta.

Sari, R., 2008, Analisa Kemampuan SDM dalam Penggunaan E-Learning, Teknik Elektro UGM, Yogyakarta.

Turban, 2005, Decision Support Systems and Intelligent Systems (Sistem Pendukung Keputusan dan Sistem Cerdas) jilid 1., Andi Offset : Yogyakarta

Wicaksono, V., 2007, Faktor Pendukung Efektifitas Penggunaan E-Learning, Teknk Elektro UGM, Yogyakarta. 